\title{
PA-113 ACHIEVEMENTS AND PRIMED PROSPECTS OF INCREASING CAPABILITIES FOR MULTISITE CLINICAL TRIALS IN THE EASTERN AFRICA NETWORK OF EXCELLENCE
}

George Miiro, ${ }^{1, \dagger}$ Edward Mbidde, ${ }^{1}$ Norbert Peshu, ${ }^{2}$ Esther Kivaya, ${ }^{2}$ Godfrey Mfinanga, ${ }^{3}$ Bernard Ngowi, ${ }^{3}$ Reginald Kavishe, ${ }^{4}$ Mukhtar Maowia, ${ }^{5}$ Trudie Lang, ${ }^{6}$ Eric Sandstrom, ${ }^{7}$ Elizabeth Ayuo, ${ }^{8}$ Annet Nanvubya, ${ }^{1}$ Blandina Mmbaga, ${ }^{4}$ Pontiano Kaleebu ${ }^{9} .{ }^{1}$ UVRI, Uganda; ${ }^{2}$ KEMRI-Wellcome Trust Research Program, Kenya; ${ }^{3}$ NIMR Muhimbili, Tanzania; ${ }^{5}$ IEND, University of Khartoum, Sudan; ${ }^{6} T G H N$, University of Oxford, United Kingdom; ${ }^{7}$ KI, Sweden; ${ }^{8}$ KEMRI-CDC, Kenya; ${ }^{9}$ MRC-UVRI AIDS, Uganda

\subsection{6/bmjgh-2016-000260.142}

Background In May 2009, EDCTP supported the establishment of the East African Consortium for Clinical Research (EACCR) involving 35 regional institutions and 6 northern partners to promote capacity development for collaborative multisite clinical trials and research. EACCR aims to contribute to overcoming a situation of: under-funded, fragmented and uncoordinated regional health research; too few African scientists; inadequate infrastructure; insufficient networking and knowledge-sharing. We present updates on achievements and lessons learnt on increased preparedness to conduct globallycompetitive research and clinical trials on poverty-related, neglected and emerging infectious diseases.

Methods Retrospectively, we conducted a quasi-purposive summative evaluation through document review, participatory appraisal, direct observation and case studies of the EACCR work packages for governance, research, training and mentoring, infrastructure, and networking between November 2015 and February 2016.

Results In the past five years, the Eastern Africa-led consensusdriven consortium has contributed to the following results (at least): 15 new research and capacity-strengthening grants; 150 peer-reviewed publications; 15 trials monitored; 531 scientists and associates mentored; 12 electronic training modules on research and bio-ethics; 2 newly ISO-accredited laboratories; 24 research sites upgraded; 20 partnerships harnessed; 2 knowledge-sharing platforms of the East African Health Research Commission; an interactive website (www. eaccr.org); and an additional 2 million euros leveraged.

Conclusions EACCR has increased its capacity and partnerships for on-going and planned multisite clinical trials; we can sustain coordinated collaborative GCP-compliant multisite trials and health research. We can intensify high-level advocacy and resource mobilisation in Eastern Africa in partnership with policy makers, other consortia and development partners. We stand firm on the shoulders of current and promising giants of EACCR, other consortia, EDCTP and other likeminded partners and are thus prepared to conduct and disseminate more African-led health research and capacitystrengthening initiatives on poverty-related, neglected and emerging infectious diseases in Africa during the second programme of EDCTP. 